\title{
Repeatability of bronchial hyperresponsiveness to adenosine-5'-monophosphate (AMP) by a short dosimeter protocol
}

\author{
G De Meer, D J J Heederik, B Brunekreef, D S Postma
}

\begin{abstract}
Background-To study bronchial responsiveness to adenosine 5'-monophosphate (AMP) in population surveys, repeatability of a rapid dosimetric method with quadrupling doses was evaluated.

Methods-Volunteers with symptoms of airway respiratory allergy or asthma were invited for AMP challenges on two occasions. After each dose the fall in forced expiratory volume in one second $\left(\mathrm{FEV}_{1}\right)$ compared with the post-saline value was determined. The cumulative doses of AMP needed to cause a fall in $\mathrm{FEV}_{1}$ of $20 \%$ $\left(\mathbf{P D}_{20}\right), 15 \%\left(\mathbf{P D}_{15}\right)$, and $10 \%\left(\mathbf{P D}_{10}\right)$ were calculated. Agreement was evaluated by means of kappa values. After excluding systematic differences in PD values on two occasions ( $t$ test), repeatability of a single estimation of the chosen PD values was calculated and expressed in doubling doses (DD).
\end{abstract}

Results-In 28 of 76 subjects a $\mathbf{P D}_{20}$ was estimated on the two visits, in 29 subjects a $\mathbf{P D}_{15}$ was estimated, and in 32 a $\mathbf{P D}_{10}$ was obtained. Kappa values for a positive threshold were 0.89 for a cut off level for a $20 \%$ fall in $\mathrm{FEV}_{1}, \mathbf{0 . 7 8}$ for a $15 \%$ fall in $\mathrm{FEV}_{1}$, and 0.76 for a fall in $\mathrm{FEV}_{1}$ of $10 \%$. The PD values did not differ between the two visits and $95 \%$ repeatability of a single estimation was $\pm 1.7 \mathrm{DD}$ for $\mathrm{PD}_{20}, \pm 2.2 \mathrm{DD}$ for $\mathrm{PD}_{15}$, and $\pm 2.4 \mathrm{DD}$ for $\mathrm{PD}_{10}$. The quadrupling dose method reduced time by $40 \%$ in non-hyperresponsive subjects and no adverse effects were observed.

Conclusion-The short dosimeter protocol with quadrupling doses for AMP challenges is a rapid, reproducible tool for estimating bronchial responsiveness in population surveys.

(Thorax 2001;56:362-365)

Keywords: adenosine-5'-monophosphate (AMP); repeatability; short dosimeter protocol; bronchial hyperresponsiveness

Pulmonology,

University Hospital,

Groningen,

Netherlands

D S Postma

Correspondence to: Dr G De Meer

G.demeer@vet.uu.nl

Received 3 December 1999 Returned to authors 14 October 2000

Revised version received

9 January 2001

Accepted for publication

12 January 2001 smooth muscle contraction. ${ }^{1}$ BHR measured by this "indirect" method may provide different information on airway lability from that obtained with directly acting stimuli.

In recent years adenosine-5'monophosphate (AMP) has been studied as an "indirect" stimulus. Although the precise mechanism by which AMP causes bronchoconstriction has not been clarified in detail, release of inflammatory mediators from mast cells plays an important role, as well as activation of nerve fibres. ${ }^{2-4}$ Several studies have indicated that airway responsiveness to AMP is a more accurate marker of bronchial inflammation in asthma than hyperresponsiveness to methacholine or histamine. Bronchial responsiveness to AMP is reduced after allergen avoidance or treatment with anti-inflammatory drugs, while responsiveness to methacholine is not. ${ }^{5-7}$ Some studies have suggested the possibility of differentiating between asthma and chronic obstructive pulmonary disease (COPD) by bronchial responsiveness to AMP, since patients with asthma have been found to have a more pronounced BHR to AMP than those with COPD. ${ }^{89}$

To date, studies on BHR to AMP have only been performed in patients with clinically diagnosed asthma or COPD. Population studies might give an insight into the value of BHR to AMP as a risk factor for asthma and determine its value in the diagnosis and therapeutic monitoring of patients with mild asthma. However, most subjects in open population studies are either not hyperresponsive or respond only at high doses, so challenge procedures using standard protocols with doubling doses (DD) until a $20 \%$ fall in forced expiratory volume in one second $\left(\mathrm{FEV}_{1}\right)$ has been reached are time consuming and may influence compliance of participants. The availability of a short protocol would make it more feasible to study BHR to AMP in an open population.

The aim of this study was to evaluate the repeatability of a short dosimeter protocol in which doses of AMP are quadrupled. To include subjects with a minor degree of airway obstruction, as in population studies, we assessed the repeatability for the cumulative dose of AMP which caused a $20 \%$ fall in $\mathrm{FEV}_{1}$ $\left(\mathrm{PD}_{20}\right)$, as well as falls of $15 \%\left(\mathrm{PD}_{15}\right)$ and $10 \%$ $\left(\mathrm{PD}_{10}\right)$.

\section{Methods}

POPULATION AND STUDY DESIGN

Volunteers aged 20-45 years were recruited from the department and from two universities. The study population consisted of 29 
volunteers in 1995 and 47 in 1998/9. In 1999 we selected subjects at risk of BHR by questionnaire on symptoms of airway allergy or asthma. AMP challenges using a protocol with quadrupling dose intervals were conducted twice at the same time of day at an interval of 2-14 days. Subjects with cardiovascular or neurological disorders were excluded, as were subjects with a baseline $\mathrm{FEV}_{1}$ of $<1.51$. Cromoglycate and antihistamines were withheld for 48 hours and $\beta$-sympathomimetic agents were withheld for 8 hours before the challenge. Subjects were asked not to smoke during the hour before testing. At the second appointment the subjects were questioned about side effects. If the second appointment was missed, subjects were approached by telephone.

In 1995 subjects were also challenged according to the standard dosimeter protocol with doubling dose intervals. A PD ${ }_{20} \mathrm{AMP}$ was obtained by both protocols in seven subjects; the standard protocol yielded a somewhat higher mean $\mathrm{PD}_{20} \mathrm{AMP}$ than the short one with a mean difference of $0.7 \mathrm{DD}$ (95\% CI 0.2 to 1.2). We decided not to include the standard protocol in the population studied in 1999 because the difference between the two protocols was small. Furthermore, the short protocol is particularly useful in epidemiological studies of subjects in whom bronchial hyperresponsiveness, if present, is usually mild and where repeatability is the predominant issue of concern.

Informed consent was obtained from each subject and the Wageningen University ethical board approved the study.

\section{LUNG FUNCTION}

In 1995 lung function was measured with a dry rolling seal spirometer (Mijnhardt, Groningen, Netherlands) and in 1999 with a pneumotachometer (Jaeger, Germany). During lung function measurement subjects were seated in an upright position, wearing a nose clip. Prior to bronchial challenge forced expiratory manoeuvres were repeated until two readings of reproducible values for $\mathrm{FEV}_{1}$ (within 5\%), forced vital capacity (FVC, within $5 \%$ ), and peak expiratory flow (PEF, within 10\%) were reached..$^{11}$ The highest $\mathrm{FEV}_{1}$ value was used

Table 1 Inhalation schemes used for AMP challenge

\begin{tabular}{|c|c|c|c|c|c|}
\hline \multirow[b]{2}{*}{$\begin{array}{l}\text { No inhalations } \\
\text { (quadrupling } \\
\text { doses) }\end{array}$} & \multirow[b]{2}{*}{$\begin{array}{l}\text { No inhalations } \\
\text { (doubling doses) }\end{array}$} & \multicolumn{2}{|c|}{ Study period $1995^{\star}$} & \multicolumn{2}{|c|}{ Study period $1999+$} \\
\hline & & $\begin{array}{l}\text { Concentration } \\
(\mathrm{mg} / \mathrm{ml})\end{array}$ & $\begin{array}{l}\text { Cumulative } \\
\text { dose (mg) }\end{array}$ & $\begin{array}{l}\text { Concentration } \\
(\mathrm{mg} / \mathrm{ml})\end{array}$ & $\begin{array}{l}\text { Cumulative } \\
\text { dose (mg) }\end{array}$ \\
\hline 4 & 4 & Saline & 0 & Saline & 0 \\
\hline 4 & 4 & 0.39 & 0.01 & 0.625 & 0.02 \\
\hline - & 1 & 1.56 & 0.03 & 2.5 & 0.04 \\
\hline 3 & 2 & 1.56 & 0.06 & 2.5 & 0.07 \\
\hline - & 1 & 6.25 & 0.11 & 10 & 0.14 \\
\hline 3 & 2 & 6.25 & 0.23 & 10 & 0.29 \\
\hline - & 1 & 25 & 0.45 & 40 & 0.58 \\
\hline 3 & 2 & 25 & 0.90 & 40 & 1.15 \\
\hline - & 1 & 100 & 1.80 & 160 & 2.30 \\
\hline 3 & 2 & 100 & 3.61 & 160 & 4.61 \\
\hline - & 2 & 200 & 7.22 & 320 & 9.21 \\
\hline 6 & 4 & 200 & 14.43 & 320 & 18.43 \\
\hline 8 & 8 & 200 & 28.86 & 320 & 36.86 \\
\hline
\end{tabular}

*Study period 1995: nebuliser output $4.10 \mu \mathrm{l} / \mathrm{s}$, inhalation time 2.2 seconds. †Study period 1999: nebuliser output $3.60 \mu \mathrm{l} / \mathrm{s}$, inhalation time 2.0 seconds. in the analyses. If no reproducible values for $\mathrm{FEV}_{1}$ were recorded, the highest of the two most consistent acceptable spirograms was used. All lung function parameters were corrected to body temperature and pressure saturated with water vapour (BTPS).

\section{AMP CHALLENGE}

Bronchial challenges were performed using a breath actuated dosimeter APS (Jaeger GmbH, Germany). The dosimeter was powered by compressed air at 20 psi. The inhalations were made from functional residual capacity (FRC) to total lung capacity (TLC) and held for 8-10 seconds. Subjects wore a nose clip during the inhalation procedure.

Nebulisers were calibrated before and after the measurement sessions. Nebuliser output was constant during the study periods. In 1995 the mean output was $4.10 \mu \mathrm{l} / \mathrm{s}$ and inhalation time was fixed at 2.2 seconds, and in 1999 mean output was $3.60 \mu \mathrm{l} / \mathrm{s}$. To avoid increasing the number of dose steps, inhalation time, or number of inhalations per dose step, AMP dilutions were concentrated compared with 1995. To assure a similar cumulative dose the inhalation time was set at 2.0 seconds for this study period.

AMP solutions were made in $0.9 \%$ saline. Table 1 shows the inhalation scheme and calculated cumulative doses for both study periods. In principle, doses were quadrupled except for the last one. Two minutes after each dose step two reproducible efforts for $\mathrm{FEV}_{1}$ were achieved. The post-saline value for $\mathrm{FEV}_{1}$ was chosen as a reference. If the post-saline $\mathrm{FEV}_{1}$ fell more than $10 \%$ compared with $\mathrm{FEV}$ before the challenge, subjects were excluded from further challenge. If $\mathrm{FEV}_{1}$ fell more than $6 \%$ compared with the reference, the test was continued with doubling doses according to the inhalation scheme. The test ended if $\mathrm{FEV}_{1}$ fell by $20 \%$ or more from the post-saline value, or after inhalation of the highest dose. Salbutamol aerosol was administered to treat bronchoconstriction, if needed.

Both the test subjects and observer were blind to the results of the first challenge, as far as possible. During the challenge no information was given about lung function results, and $\mathrm{FEV}_{1}$ values of previous dose steps were not visible to the observer.

\section{DATA ANALYSIS}

Cumulative doses of inhaled AMP causing a fall in $\mathrm{FEV}_{1}$ of $20 \%\left(\mathrm{PD}_{20}\right), 15 \%\left(\mathrm{PD}_{15}\right)$, and $10 \%\left(\mathrm{PD}_{10}\right)$ were calculated. The cumulative dose needed to cause this fall in $\mathrm{FEV}_{1}$ was estimated by linear interpolation between the last two points. To increase the number of subjects with a positive threshold we did separate analyses by including PD values determined by extrapolation over one doubling dose (DD).

Kappa values were calculated for the agreement of a positive threshold. For calculation of the mean difference in PD values and the repeatability of a single estimation, the PD values were $\log _{2}$ transformed to express differences in DD, which is equivalent to the number 
Table 2 Agreement of positive and negative thresholds measured on two occasions and kappa values at cut off levels of $20 \%, 15 \%$ and $10 \%$ fall in FEV $(n=75)$

\begin{tabular}{llllllll}
\hline & \multicolumn{2}{l}{ Extrapolated PD values excluded } & & \multicolumn{3}{l}{ Extrapolated } & \multicolumn{2}{l}{ PD values included } \\
\cline { 2 - 3 } & $\begin{array}{l}\text { Positive } \\
\text { threshold }\end{array}$ & $\begin{array}{l}\text { Negative } \\
\text { threshold }\end{array}$ & $\begin{array}{l}\text { Kappa } \\
\text { value }\end{array}$ & & $\begin{array}{l}\text { Positive } \\
\text { threshold }\end{array}$ & $\begin{array}{l}\text { Negative } \\
\text { threshold }\end{array}$ & $\begin{array}{l}\text { Kappa } \\
\text { value }\end{array}$ \\
\hline $\mathrm{PD}_{20}$ & 28 & 43 & 0.89 & & 31 & 37 & 0.81 \\
$\mathrm{PD}_{15}$ & 29 & 38 & 0.78 & & 34 & 30 & 0.70 \\
$\mathrm{PD}_{10}$ & 32 & 34 & 0.76 & & 38 & 32 & 0.61 \\
\hline
\end{tabular}

$\mathrm{PD}_{20}, \mathrm{PD}_{15}, \mathrm{PD}_{10}=$ dose of $\mathrm{AMP}$ provoking a fall in forced expiratory volume in one second $\left(\mathrm{FEV}_{1}\right)$ of $20 \%, 15 \%$, and $10 \%$, respectively.

of dose steps in a standard dosimeter protocol. ${ }^{12}$ To estimate the repeatability of a single PD value we used the stepwise method described by Bland and Altman. ${ }^{13}$ Firstly, a paired $t$ test was used to test for a systematic difference in reference $\mathrm{FEV}_{1}$ and PD values. The difference in PD values was then plotted against their mean to evaluate a potential relationship. After excluding the probability of systematic differences, the limits of agreement were calculated as the mean difference $\pm 2 \mathrm{SD}$; these were considered meaningful for use in epidemiological studies if they did not exceed \pm 3 DD. ${ }^{11}$ The repeatability of a single estimation of the PD value was calculated from the $95 \%$ range of a single measurement using the formula: $t_{0.05} \times \mathrm{SD}$ (within subject). The within subject SD was calculated by dividing the SD of the difference in $\log _{2}$ (PD) by the square root of 2 . The calculated repeatability was expressed as a doubling dose interval ( $\log _{2}$ equivalent) and reflects agreement between tests for an individual.

To test whether the change in equipment influenced the results, separate analyses were performed for each study period.

\section{Results}

Of the 76 subjects studied, 75 (47 women, 28 men) of mean age 29 years (range 20-45) completed the study protocol with two AMP challenges. The mean period between the tests was 7 days (range 2-14).

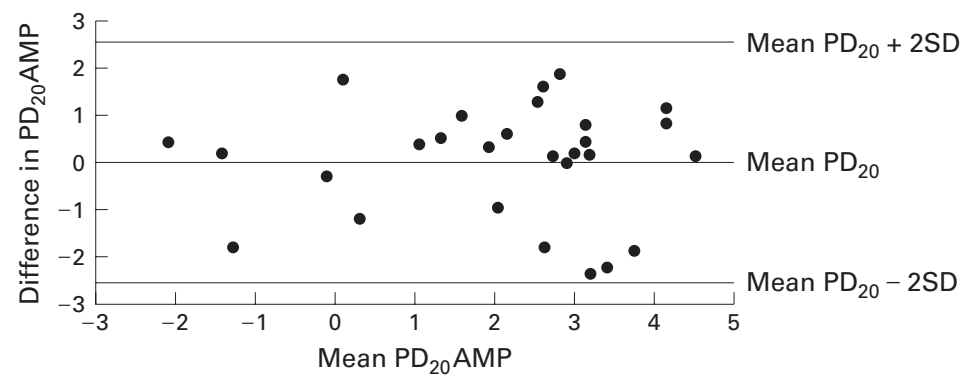

Figure 1 Difference between the two $P D_{20}$ values against the mean $P D_{20}$ (in $\left.\log _{2} P D_{20} A M P\right)$.

Table 3 Mean difference in $P D_{20}, P D_{15}$, and $P D_{10}$ (with 95\% CI), and 95\% repeatability in doubling doses AMP

\begin{tabular}{|c|c|c|c|c|c|c|}
\hline & \multicolumn{3}{|c|}{ Extrapolated PD values excluded } & \multicolumn{3}{|c|}{ Extrapolated PD values included } \\
\hline & No & Difference $\log _{2}(P D)$ & $\begin{array}{l}95 \% \\
\text { repeatability }\end{array}$ & No & Difference $\log _{2}(P D)$ & $\begin{array}{l}95 \% \\
\text { repeatability }\end{array}$ \\
\hline $\mathrm{PD}_{20}$ & 28 & $0.0(-0.5$ to 0.4$)$ & \pm 1.7 & 31 & $0.0(-0.4$ to 0.4$)$ & \pm 1.6 \\
\hline $\mathrm{PD}_{15}$ & 29 & $0.4(-0.2$ to 0.9$)$ & \pm 2.2 & 34 & $0.6(0.0$ to 1.2$)$ & \pm 2.4 \\
\hline $\mathrm{PD}_{10}$ & 32 & $0.3(-0.3$ to 0.9$)$ & \pm 2.4 & 38 & $0.4(-0.2$ to 0.9$)$ & \pm 2.5 \\
\hline
\end{tabular}

$\mathrm{PD}_{20}, \mathrm{PD}_{15}, \mathrm{PD}_{10}=$ dose of $\mathrm{AMP}$ provoking a fall in forced expiratory volume in one second $\left(\mathrm{FEV}_{1}\right)$ of $20 \%, 15 \%$, and $10 \%$, respectively.; AMP = adenosine-5'-monophosphate.
Table 2 shows the agreement of a threshold at the defined cut off levels for a fall in $\mathrm{FEV}_{1}$ of $20 \%, 15 \%$, and $10 \%$. The agreement of a positive threshold between the two tests was $94.5 \%$ for $\mathrm{PD}_{20}, 89.3 \%$ for $\mathrm{PD}_{15}$, and $88.0 \%$ for $\mathrm{PD}_{10}$. The kappa value was highest for $\mathrm{PD}_{20}$ and lowest for $\mathrm{PD}_{10}$, with $\mathrm{PD}_{15}$ intermediate. The inclusion of PD values achieved by extrapolation did not change the kappa values markedly, except for $\mathrm{PD}_{10}$.

Figure 1 and table 3 show the repeatability of the actual PD values obtained. As shown in fig 1 , there was no relation between the difference and the mean $\mathrm{PD}_{20}$ values at the two visits, allowing calculation of repeatability for the whole range of mean $\mathrm{PD}_{20}$ values. The limits of agreement were between -2.4 and $+2.4 \mathrm{DD}$. Similarly, no relation between the difference and the mean values was seen for $\mathrm{PD}_{15}$ or $\mathrm{PD}_{10}$. Pre-challenge $\mathrm{FEV}_{1}$ values (3.80 1 and $3.75 \mathrm{l}$ ) and PD values were the same at both visits, and the $95 \%$ repeatability of a single measurement was within 2-3 DD for all PD values, irrespective of whether or not extrapolated PD values were included. Exclusion of subjects measured in 1995, of whom three had a $\mathrm{PD}_{20}$, did not change the results.

In non-responsive subjects the AMP challenge using the quadrupling dose protocol took 25-30 minutes. No adverse reactions were observed during or after the challenge.

\section{Discussion}

In this study we have evaluated the repeatability of AMP challenges using quadrupling doses. According to the kappa value, the agreement was very good if BHR was defined as a fall in $\mathrm{FEV}_{1}$ of $20 \%$. The $95 \%$ repeatability for a single measurement of $\mathrm{PD}_{20}$ was $\pm 1.7 \mathrm{DD}$. In non-responsive subjects the short protocol took 25-30 minutes, resulting in a time gain of at least $40 \%$ compared with the standard dosimeter protocol using doubling doses. No adverse effects were reported during or after the challenge.

According to the kappa values the agreement for both the positive and negative thresholds was very good for $\mathrm{PD}_{20}$ and good for $\mathrm{PD}_{15}$ and $\mathrm{PD}_{10}$. However, the agreement of a negative threshold should be interpreted with caution as our population was not a random sample (in the second part of the study we selected subjects based on an increased chance of having $\mathrm{BHR}$ ). Kappa values were almost the same if the definition of BHR was based on extrapolated PD values, except for the threshold defined by $\mathrm{PD}_{10}$. The agreement was similar for BHR defined by $\mathrm{PD}_{10}$ without extrapolated values and $\mathrm{PD}_{15}$ with extrapolated values. Thus, reproducibility is acceptable when using $\mathrm{PD}_{20}$ or $\mathrm{PD}_{15}$ values obtained by extrapolation over one doubling dose, but for $\mathrm{PD}_{10}$ extrapolation should be avoided as it has a considerable effect on reproducibility.

We did not find any difference in PD values between the two tests. The repeatability of a single $\mathrm{PD}_{20}$ value was similar to that in other studies which have evaluated short protocols for methacholine and histamine challenges. ${ }^{14-17}$ One study assessed the repeatability of 
$\mathrm{PD}_{20} \mathrm{AMP}$ and found limits of agreement between -4.54 and $3.78 \mathrm{DD} .{ }^{18}$ In this study the $95 \%$ repeatability for a single $\mathrm{PD}_{20} \mathrm{AMP}$ was $\pm 3.1 \mathrm{DD}$. The cut off value for a $20 \%$ fall in $\mathrm{FEV}_{1}$ is a diagnostic criterion for obstructive airway disease which might be too restrictive for use in an open population. We therefore also determined the repeatability of $\mathrm{PD}_{15}$ and $\mathrm{PD}_{10}$ values that were both within the limit of 3 DD. Similar results were achieved for extrapolated PD values. The decision as to which cut off value should be used to define BHR has to be studied in relation to other measures of obstructive airway disease, particularly respiratory symptoms and lung function impairment.

We found a relatively large difference in both kappa values and $95 \%$ repeatability for $\mathrm{PD}_{20}$ compared with $\mathrm{PD}_{15}$ or $\mathrm{PD}_{10}$. Van Aalderen et al also determined the reproducibility of histamine challenge for $\mathrm{PD}_{20}, \mathrm{PD}_{15}$, and $\mathrm{PD}_{10}$ values and did not find a difference in repeatability. ${ }^{19}$ In our study there was no learning effect with respect to the performance of forced spirometric tests since baseline $\mathrm{FEV}_{1}$ was the same on both occasions. Circadian and seasonal variation did not affect the tests because measurements were made at the same time of day during all seasons and there was no timedependent trend. Refractoriness to AMP can also be excluded since there were at least 2 days between the tests and, according to the literature, tachyphylaxis for repeated AMP challenges lasts only about 4 hours. ${ }^{20}$ Since there was no difference in $\mathrm{PD}_{20}$ between the two tests, bias resulting from knowledge of the first test results is unlikely. The slightly higher values for $\mathrm{PD}_{15}$ and $\mathrm{PD}_{10}$ at the second visit may be attributed to a training effect to complete the test. Both physical and psychological factors may play a part, with subjects being less exhausted by repeated lung function manoeuvres and anticipating the end of the test on the second occasion. The most likely explanation for the observed discrepancy in the kappa values and $95 \%$ repeatability for $\mathrm{PD}_{15}$ and $\mathrm{PD}_{10}$ compared with $\mathrm{PD}_{20}$ is a more precise measurement of a $20 \%$ fall in $\mathrm{FEV}_{1}$. The test protocol was fixed to a fall in $\mathrm{FEV}_{1}$ of $20 \%$, and it might be that the examiner was more alert if the fall in $\mathrm{FEV}_{1}$ approximated this which may have resulted in increasing encouragement during lung function measurement ensuring a more accurate measurement of $\mathrm{FEV}_{1}$. Since $\mathrm{PD}_{15}$ and $\mathrm{PD}_{10}$ have been determined after the fieldwork, they will not have been biased in this way. However, one could equally well argue that the repeatability of these indices is underestimated because of less precise measurement of lung function at these cut off $\mathrm{FEV}_{1}$ values.

In summary, the reproducibility of a single estimation of $\mathrm{PD}_{20}, \mathrm{PD}_{15}$, and $\mathrm{PD}_{10}$ measured by a short dosimeter protocol with quadrupling doses is within 2-3 DD. The agreement between two determinations of BHR to AMP is good. The time needed to test nonhyperresponsive subjects is $25-30$ minutes, and there are no adverse effects. We conclude that the short protocol is an acceptable and reproducible tool to test $\mathrm{BHR}$ in population surveys which may increase participation and reduce costs and logistical management of bronchial challenges.

The authors are grateful to the volunteers who participated in this study and to $S$ de Wind and $S$ van Gaans for their technical assistance. This study was supported by a grant from the Netherlands Asthma Fund and the Foundation Asthma Abatement.

1 Polosa R, Holgate ST. Adenosine bronchoprovocation: a promising marker of allergic inflammation in asthma? Tho$\operatorname{rax} 1997 ; 52: 919-23$

2 Cushley MJ, Holgate ST. Adenosine-induced bronchoconstriction in asthma: role of mast cell-mediator release. $\mathcal{F}$ Allergy Clin Immunol 1985; 75:272-8.

3 Polosa R, Phillips GD, Rajakulasingam K, et al. The effect of inhaled ipratropium bromide alone and in combination with oral terfenadine on bronchoconstriction provoked by adenosine 5'-monophosphate and histamine in asthma. $\mathcal{F}$ Allergy Clin Immunol 1991;87:939-47.

4 Crimi N, Palermo F, Oliveri F, et al. Protective effects of inhaled ipratropium bromide on bronchoconstriction nduced by adenosine and methacholine in asthma. Eur Respir F 1992;5:560-5.

5 van Velzen E, van den Bos JW, Benckhuijsen JA, et al. Effect of allergen avoidance at high altitude on direct and indirect bronchial hyperresponsiveness and markers of inflammation in children with allergic asthma. Thorax 1996;51:5824.

6 Weersink EJ, Douma RR, Postma DS, et al. Fluticasone propionate, salmeterol xinafoate, and their combination in
the treatment of nocturnal asthma. Am $\mathcal{F}$ Respir Crit Care Med 1997;155:1241-6.

7 Taylor DA, Jensen MW, Kanabar V, et al. A dose-dependent effect of the novel inhaled corticosteroid ciclesonide on airway responsiveness to adenosine-5'-monophosphate in asthmatic patients. Am ₹ Respir Crit Care Med 1999;160: 237-43.

8 Avital A, Springer C, Bar-Yishay E, et al. Adenosine, methacholine, and exercise challenges in children with asthma or paediatric chronic obstructive pulmonary disease. Thorax 1995;50:511-6.

9 Oosterhoff Y, de Jong JW, Jansen MA, et al. Airway responsiveness to adenosine 5'-monophosphate in chronic obstructive pulmonary disease is determined by smoking. $\mathrm{Am}$ Rev Respir Dis 1993;147:553-8.

10 Quanjer PH. Standardised lung function testing. Bull Eur Physiopathol Respir 1983;Suppl 5:1-95.

11 Sterk PJ, Fabbri LM, Quanjer PH, et al. Airway responsiveness. Standardized challenge testing with pharmaceutical, physical and sensitizing stimuli in adults. Official statement of the European Respiratory Society. Eur Respir f 1993;6:53-83.

12 Peat JK, Unger WR, Combe D. Measuring changes in logarithmic data, with special reference to bronchial responsiveness. $\mathcal{F}$ Clin Epidemiol 1994;47:1099-108.

13 Bland JM, Altman DG. Statistical methods for assessing agreement between two methods of clinical measurement. Lancet 1986;i:307-10.

14 Knox AJ, Wisniewski A, Cooper S, et al. A comparison of the Yan and a dosimeter method for methacholine challenge in experienced and inexperienced subjects. Eur Respir F 1991; 4:497-502.

15 Kremer AM, Pal TM, Oldenziel M, et al. Use and safety of a shortened histamine challenge test in an occupational study. Eur Respir F 1995;8:737-41.

16 Chinn S, Britton JR, Burney PG, et al. Estimation and repeatability of the response to inhaled histamine in a community survey. Thorax $1987 ; 42: 45-52$.

17 Peat JK, Salome CM, Bauman A, et al. Repeatability of histamine bronchial challenge and comparability with methacholine bronchial challenge in a population of Australian schoolchildren. Am Rev Respir Dis 1991;144:338-43.

18 Egbagbe E, Pavord ID, Wilding P, et al. Adenosine monophosphate and histamine induced bronchoconstriction: repeatability and protection by terbutaline. Thorax 1997;52:239-43

19 van Aalderen W, Gerritsen J, Koeter GH, et al. The reproducibility and agreement of three indices of airway responsiveness to histamine in asthmatic children. Pediatr Pulmonol 1989;6:113-7.

20 Daxun Z, Rafferty P, Richards R, et al. Airway refractoriness to adenosine 5'-monophosphate after repeated inhalation. $\mathcal{F}$ Allergy Clin Immunol 1989;83:152-8. 